\title{
CFTR is required for PKA-regulated ATP sensitivity of Kir1.1 potassium channels in mouse kidney
}

\author{
Ming Lu, ${ }^{1}$ Qiang Leng, ${ }^{1}$ Marie E. Egan, ${ }^{2}$ Michael J. Caplan, ${ }^{1}$ Emile L. Boulpaep, ${ }^{1}$ \\ Gerhard H. Giebisch, ${ }^{1}$ and Steven C. Hebert ${ }^{1}$
}

1Department of Cellular and Molecular Physiology and 'Department of Pediatrics, Yale University School of Medicine, New Haven, Connecticut, USA.

\begin{abstract}
The cystic fibrosis transmembrane conductance regulator (CFTR) $\mathrm{Cl}^{-}$channel plays vital roles in fluid transport in many epithelia. While CFTR is expressed along the entire nephron, its function in renal tubule epithelial cells remains unclear, as no specific renal phenotype has been identified in cystic fibrosis. CFTR has been proposed as a regulator of the $30 \mathrm{pS}$, ATP-sensitive renal $\mathrm{K}$ channel (Kir1.1, also known as renal outer medullar $\mathrm{K}$ [ROMK]) that is critical for $\mathrm{K}$ secretion by cells of the thick ascending limb (TAL) and distal nephron segments responsive to aldosterone. We report here that both ATP and glibenclamide sensitivities of the $30 \mathrm{pS}$ $\mathrm{K}$ channel in TAL cells were absent in mice lacking CFTR and in mice homozygous for the $\triangle \mathrm{F} 508$ mutation. Curcumin treatment in $\triangle$ F508-CFTR mice partially reversed the defect in ATP sensitivity. We demonstrate that the effect of CFTR on ATP sensitivity was abrogated by increasing PKA activity. We propose that CFTR regulates the renal $\mathrm{K}$ secretory channel by providing a PKA-regulated functional switch that determines the distribution of open and ATP-inhibited $\mathrm{K}$ channels in apical membranes. We discuss the potential physiological role of this functional switch in renal $\mathrm{K}$ handling during water diuresis and the relevance to renal $\mathrm{K}$ homeostasis in cystic fibrosis.
\end{abstract}

\section{Introduction}

The regulation of salt and water excretion by the kidney is crucial for volume and osmotic homeostasis and requires the complex coordinated effects of many different ion, water, and solute transport proteins that are differentially distributed along the nephron. Cystic fibrosis transmembrane conductance regulator (CFTR) is a cAMP-dependent, PKA-regulated $\mathrm{Cl}^{-}$channel (1) that is highly expressed in all segments of the mammalian nephron (2-6). While CFTR plays vital roles in fluid transport in many epithelia, such as those from lung, sweat duct, and intestine, its function in renal tubule epithelial cells remains unclear $(2,7)$. This is underscored by the apparent lack of an overt renal phenotype in cystic fibrosis.

CFTR not only functions as a $\mathrm{Cl}^{-}$channel but has also been proposed as a regulator of other ion channels, including the renal secretory renal outer medullar potassium (ROMK) channel (8-11). ROMK (or Kir1.1; gene Kcnj1) is a $30 \mathrm{pS} \mathrm{K}$ channel that is a member of the inward rectifier family of $\mathrm{K}$ channels (Kir; ref. 11) which also includes the ATP-sensitive $\mathrm{K}$ channels ( $\mathrm{K}_{\mathrm{ATP}}$, Kir6.x; ref. 12). ROMK mediates apical $\mathrm{K}$ recycling in the thick ascending limb (TAL) and net K secretion by aldosterone-sensitive distal nephron cells in the connecting segment and cortical collecting duct (CCD) $(11,13)$. Loss-of-function mutations in the human ROMK gene (KCNJ1) cause type II Bartter syndrome with renal salt wasting (14, $15)$, consistent with the crucial role of ROMK in supporting $\mathrm{NaCl}$

Nonstandard abbreviations used: AVP, arginine vasopressin; CCD, cortical collecting duct; CFTR, cystic fibrosis transmembrane conductance regulator; IBMX, 3-isobutyl-1-methylxanthine; NHERF, $\mathrm{Na}^{+} / \mathrm{H}^{+}$exchange regulatory factor; $\mathrm{NPD}$, nasal potential difference; $N P_{\mathrm{o}}$, ROMK channel activity; PDZ, PSD95/DLG/ZO-1 (proteins); $P_{\mathrm{o}}$, open probability; ROMK, renal outer medullar potassium; RPD, rectal potential difference; SUR, sulfonylurea receptor; TAL, thick ascending limb; -V, holding potential.

Conflict of interest: The authors have declared that no conflict of interest exists. Citation for this article: J. Clin. Invest. 116:797-807 (2006). doi:10.1172/JCI26961. reabsorption in the TAL. Studies in the ROMK-null mouse (16) have confirmed that ROMK forms the $30 \mathrm{pS}$ K recycling/secretory channel in the TAL and collecting duct (17) and is also required for expression of the $70 \mathrm{pS} \mathrm{K}$ recycling channel in the TAL (18).

ROMK channel expression and function is intricately regulated by a wide variety of factors, including intracellular $\mathrm{pH}$ and both extracellular and cytosolic ATP (11). Mg-ATP concentrations of $\geq 1 \mathrm{mM}$ and micromolar concentrations of the sulfonylurea glibenclamide inhibit the $30 \mathrm{pS} \mathrm{K}$ channels in the TAL and CCD (19). In vitro studies have suggested that CFTR may be required for inhibition of ROMK by cytosolic ATP (20) and glibenclamide (20, 21). These in vitro effects of CFTR on ROMK function are likely mediated through binding of both proteins via PSD95/DLG/ZO-1 (PDZ) interactions to the scaffolding protein $\mathrm{Na}^{+} / \mathrm{H}^{+}$exchange regulatory factor (NHERF; ref. 22) and require the transmembrane domain 1 , the first nucleotide-binding fold, and the regulatory domain on CFTR $(23,24)$. In addition, CFTR-ROMK functional interaction can be regulated by cAMP-dependent protein kinase A (PKA), since increasing cAMP abrogates the effect of CFTR on glibenclamide sensitivity of ROMK in Xenopus laevis oocytes (21). However, other ABC proteins, the sulfonylurea receptors (SUR1/2), have been implicated in the effect of glibenclamide on ROMK (25) as well as ATP and glibenclamide sensitivities of the other ATP-sensitive inward rectifier channels ( $\mathrm{K}_{\mathrm{ATP}}$, Kir6.x; refs. 12, 13, 26). Since SUR mRNA and protein are expressed in the distal nephron (11), the potential role of CFTR on ROMK function in vivo is unclear.

In the present study we examined whether CFTR is required for ATP sensitivity of ROMK in mouse kidney and whether CFTR's effects are altered by cAMP/PKA. Studies were performed using 2 different mouse models of cystic fibrosis, a CFTR-null strain (cftr ${ }^{\text {tm } 1 U n c_{-}} c f t r^{b F A B P}$; ref. 27) and a $\Delta$ F508-CFTR strain (cftr ${ }^{t m 1 K t h}$; ref. 28). In each model, ATP and glibenclamide sensitivities were drastically reduced or eliminated, consistent with CFTR as a criti- 

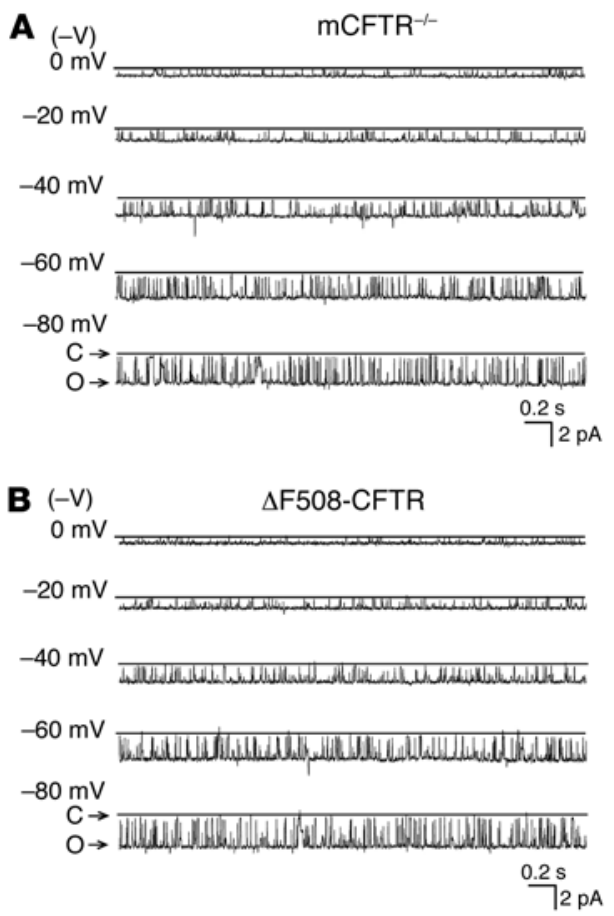
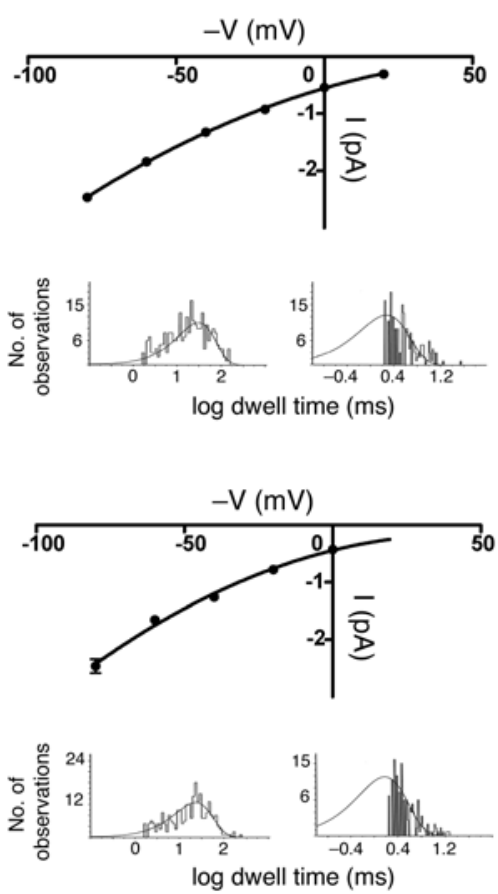

\section{Figure 1}

Electrophysiological characteristics of ROMK channels in the apical membrane of mouse cortical TAL. Representative single-channel recordings of a cftrtm1Unc-cftrhFABP transgenic mouse (mCFTR $\left.{ }^{-1-} ; \mathbf{A}\right)$ and a $\mathrm{cftr}^{\mathrm{tm} 1 \mathrm{Kth}^{\text {th }}}$ transgenic mouse ( $\triangle$ F508-CFTR; B) ROMK channel in an inside-out patch configuration at different $-\mathrm{V}$ : $0,-20,-40,-60$ and $-80 \mathrm{mV}$ (left). Maximally open state $(\mathrm{O})$ and complete channel closure (C) are indicated. Single-channel I-V curve (A, upper right) shows slight inward rectification with a slope conductance of $32.1 \mathrm{pS}$. The $\Delta$ F508-CFTR mouse had similar electrophysiological characteristics to the $\mathrm{mCFTR}^{-/-}$mouse (lower right). I(pA), current in picoamperes. cal subunit of the $30 \mathrm{pS} \mathrm{K}$ channel. Moreover, in wild-type mice expressing CFTR, elevation of PKA activity also eliminated the sensitivity of ROMK to cytosolic concentrations of ATP. We discuss the implications of these findings for the function of ROMK in antidiuretic and water diuretic states.

\section{Results}

ROMK channel expression, single-channel electrical properties, and gating by $\mathrm{pH}$ are unaltered in CFTR-null and $\triangle F 508$-CFTR mice. In Kir6.2 $\mathrm{K}_{\mathrm{ATP}}$ channels, interaction with SUR is required for normal trafficking of the K channel complex to the plasma membrane (29). In addition, coexpression of human CFTR with ROMK1 in X. laevis oocytes was suggested to reduce the single-channel conductance of ROMK (20). Thus we first examined whether the absence of mouse CFTR expression (cftrtm1Unc-cftr ${ }^{\text {bFABP }}$ transgenic mouse, mCFTR ${ }^{-1-}$; ref. 27) or mouse CFTR trafficking to the plasma membrane with the $\Delta$ F508 mutation ( $c f_{t r}{ }^{\text {tm } 1 K \text { th }}$ transgenic mouse, $\Delta F 508$-CFTR; ref. $28)$ altered ROMK channel activity $\left(N P_{o}\right.$; see "Statistics" in Methods), measured as number of channels $(N) \times$ single-channel open probability $\left(P_{\mathrm{o}}\right)$, or single-channel characteristics in TAL cells. Figure 1, A and B, shows typical K channel current traces from excised, inside-out patches of cortical TAL apical membranes from both CFTR transgenic mouse models. The associated I-V curves showed slight inward rectification typical for ROMK (17). Table 1 shows that the average singlechannel conductance and $P_{\mathrm{o}}$ was not different from our previous observations in TAL from wild-type mice (17). The dwell-time histograms (Figure 1, A and B) show 1 open time and 1 closed time that were similar to those in patches of TAL from wild-type mice (Table 1; ref. 17). Thus, CFTR is not required for trafficking of ROMK to the plasma membrane of TAL cells, and the absence of CFTR at the plasma membrane does not alter singlechannel electrical properties of ROMK.
Cytosolic-side $\mathrm{pH}$ provides an important and fundamental gating mechanism for ROMK, with reductions in $\mathrm{pH}$ to $\leq 6.9$ reversibly inhibiting channel activity (11). To determine whether the absence of CFTR at the plasma membrane globally affects the gating of ROMK, we examined the effect of $\mathrm{pH}$ on ROMK channel activity. Figure 2 shows that $N P_{\mathrm{o}}$ was reversibly inhibited in both wild-type and $\mathrm{mCFTR}^{-/-}$mice by lowering cytosolic $\mathrm{pH}$ from 7.4 to 6.9 (Figure 2, A and $\mathrm{B}$ ). $N P_{\mathrm{o}}$ decreased in wildtype mice from $5.02 \pm 0.82$ to $0.05 \pm 0.02(n=4)$ and in $\mathrm{mCFTR}^{-/}$ mice from $6.72 \pm 0.23$ to $0.04 \pm 0.01(n=5)$. Thus the absence of CFTR did not affect the ability of ROMK to be inhibited by an acidic cytosolic $\mathrm{pH}$.

CFTR is not required for regulation by extracellular ATP or low concentrations of intracellular ATP. ROMK is complexly regulated by both extracellular and intracellular ATP (11), and one potential way in which CFTR could modulate ROMK activity is by affecting one of these regulatory mechanisms. For example, purinergic receptors are expressed along the entire nephron (30), and extracellular ATP has been shown to inhibit the apical $30 \mathrm{pS}$ ROMK channel in mouse CCD principal cells through activation of a $\mathrm{P}_{2} \mathrm{Y}_{2}$ receptor in the apical membrane (31). In addition, CFTR has been postulated to mediate efflux of ATP out of the cell (32) or to enhance another

\section{Table 1}

Single-channel characteristics of the apical $\mathrm{K}$ channel in distinct CFTR genotypes

$\begin{array}{lcccc}\text { Genotype } & \mathbf{G}(\mathbf{p S}) & \boldsymbol{P}_{\mathbf{0}} & \mathbf{T}_{\mathbf{0}}(\mathbf{m s}) & \mathbf{T}_{\mathbf{c}}(\mathbf{m s}) \\ \text { Wild-type }(n=4)^{\mathrm{A}} & 31.5 \pm 0.23 & 0.88 \pm 0.02 & 28.28 \pm 0.23 & 1.21 \pm 0.13 \\ \text { mCFTR }^{--}(n=4) & 32.1 \pm 0.12 & 0.87 \pm 0.16 & 30.47 \pm 1.21 & 1.69 \pm 1.23 \\ \text { DF508-CFTR }(n=3) & 30.46 \pm 0.28 & 0.89 \pm 0.13 & 24.59 \pm 2.94 & 1.51 \pm 0.46\end{array}$

Channel conductance $(\mathrm{G})$ was calculated between -40 and $-80 \mathrm{mV}$ from inside-out patches. ${ }^{A}$ Data cited from ref. 17. $T_{0}$, open time; $T_{c}$, closed time. 

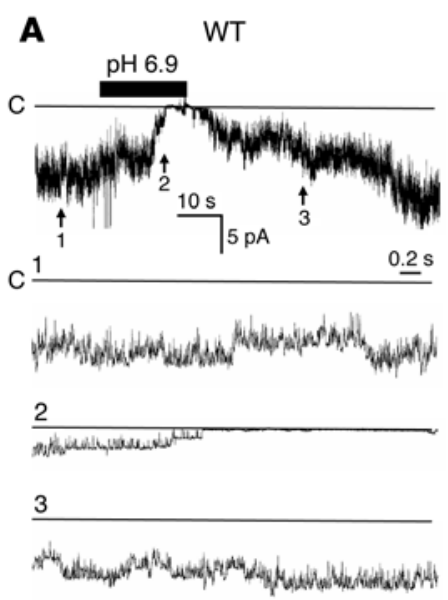
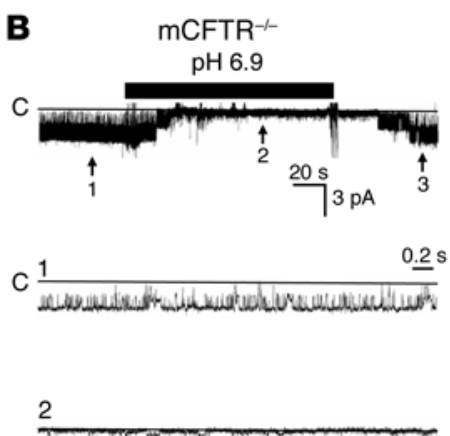

3

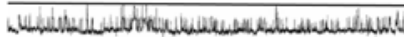

\section{Figure 2}

$\mathrm{pH}$ sensitivity of ROMK in the apical membrane of TAL from wildtype and $\mathrm{mCFTR}^{-/-}$mice. Single-channel recordings show $\mathrm{pH}$ 6.9 reversibly inhibited ROMK channels in inside-out patches in both wild-type (A) and $\mathrm{mCFTR}^{-/}$(B) mice. Bottom: Fast time resolution tracings obtained at time points indicated by corresponding numbered arrows at top. type of ATP release mechanism (33) that in turn could influence cell function via purinergic receptors (34). While we cannot directly assess the role of CFTR in ATP efflux, we did examine whether the absence of CFTR alters the inhibition of ROMK channels by extracellular ATP. Figure 3A shows a typical channel recording in a cell-attached patch on TAL cells, in which extracellular addition of $200 \mu \mathrm{M}$ Mg-ATP reversibly inhibited ROMK channel activity. $N P_{\mathrm{o}}$ decreased from $4.23 \pm 1.24$ to $0.02 \pm 0.01$ with ATP and returned to the control level following washout $(4.22 \pm 1.31 ; n=5)$. This confirmed that extracellular ATP not only modulates ROMK activity in the principal cells (31) from CCDs, but also in TAL cells (Figure 3A). In addition, the absence of mouse CFTR did not alter the effect of extracellular ATP (Figure 3B) in TAL cells. In $\mathrm{mCFTR}^{-/-}$mice, $N P_{\mathrm{o}}$ decreased from $3.89 \pm 2.01$ to $0.01 \pm 0.02$ with ATP and returned to the control level following washout $(3.88 \pm 1.69 ; n=6)$.

ROMK channel activity is also enhanced by low (i.e., micromolar) concentrations of intracellular Mg-ATP via phosphorylation processes including PKA phosphorylation of $\operatorname{ROMK}(35,36)$ and lipid kinase-mediated formation of $\mathrm{PIP}_{2}$ (37-39). Figure 4 shows 2 representative current recordings in inside-out patches from wild-type and $\mathrm{CFTR}^{-/-}$mice in a $\mathrm{Mg}$-ATP- and $\mathrm{Ca}^{2+}$-free bath solution. ROMK channels showed rapid rundown after excision in the inside-out configuration in ATP- and $\mathrm{Ca}^{2+}$-free bath solution (37-39). Consistent with previous findings, addition of 100-500 $\mu \mathrm{M}$ Mg-ATP reactivated the rundown ROMK channels in both wild-type and CFTR ${ }^{-/-}$mice. In TAL from wild-type mice, activity in inside-out patches from TAL or principal cells (40). In vitro studies in $X$. laevis oocytes suggest that these inhibitors of ROMK require coexpression of CFTR $(20,21)$. The effects of glibenclamide in representative current traces from inside-out patches of apical membranes from wild-type and $\mathrm{mCFTR}^{-/}$mice are shown in Figure 5, A and B, and the data are summarized in Figure 5C. Addition of $20 \mu \mathrm{M}$ glibenclamide reversibly inhibited wild-type ROMK channel activity (Figure $5 \mathrm{~A}$ ); $N P_{\mathrm{o}}$ decreased from $0.84 \pm 0.08$ to $0.12 \pm 0.03$ and returned to $0.84 \pm 0.06$ with washout $(P<0.05$, glibenclamide versus control and washout; $n=4)$. If CFTR interacts with ROMK to form the apical $30 \mathrm{pS} \mathrm{K}$ channel in the TAL and is required for glibenclamide sensitivity of this channel, then deletion of the mouse CFTR gene should reduce the effect of this sulfonylurea on ROMK. Indeed, a 10-fold higher concentration of glibenclamide had no effect on ROMK activity in TAL from $\mathrm{CFTR}^{-/}$- mice (Figure $5 \mathrm{~B}$ ). $N P_{\mathrm{o}}$ was $0.87 \pm 0.15$ and $0.86 \pm 0.16$ in the absence and presence of $200 \mu \mathrm{M}$ glibenclamide, respectively $(P=\mathrm{NS} ; n=4)$. Figure $5 \mathrm{C}$ shows that the sensitivity of the $30 \mathrm{pS} \mathrm{K}$ channel to glibenclamide was markedly right-shifted in $\mathrm{mCFTR}^{-1}$ mice. The $\mathrm{IC}_{50}$ for glibenclamide in wild-type mice was $15 \mu \mathrm{M}$ (Hill coefficient $=4.4 \pm 0.4$ ), and in $\mathrm{mCFTR}^{-/-}$mice, $675 \mu \mathrm{M}$ (Hill coefficient $=1.6 \pm 0.4)$.

Figure 6 shows that the inhibition of $30 \mathrm{pS} \mathrm{K}$ channel activity by cytosolic Mg-ATP in excised inside-out patches of TAL cells was virtually abolished in the absence of CFTR in the apical membrane. Figure 6A shows a representative current trace from a

\section{Figure 3}

Extracellular ATP inhibits the ROMK channel in the apical membrane of TAL. Low concentration of Mg-ATP $(200 \mu \mathrm{M})$ reversibly reduced ROMK channel activity in cell-attached patches, likely through stimulation of a $\mathrm{P}_{2} \mathrm{Y}_{2}$ receptor, in wild-type $(\mathbf{A})$ and $\mathrm{mCFTR}^{-/-}$mice $(\mathbf{B})$ held at $\mathrm{a}-\mathrm{V}$ of $0 \mathrm{mV}$.
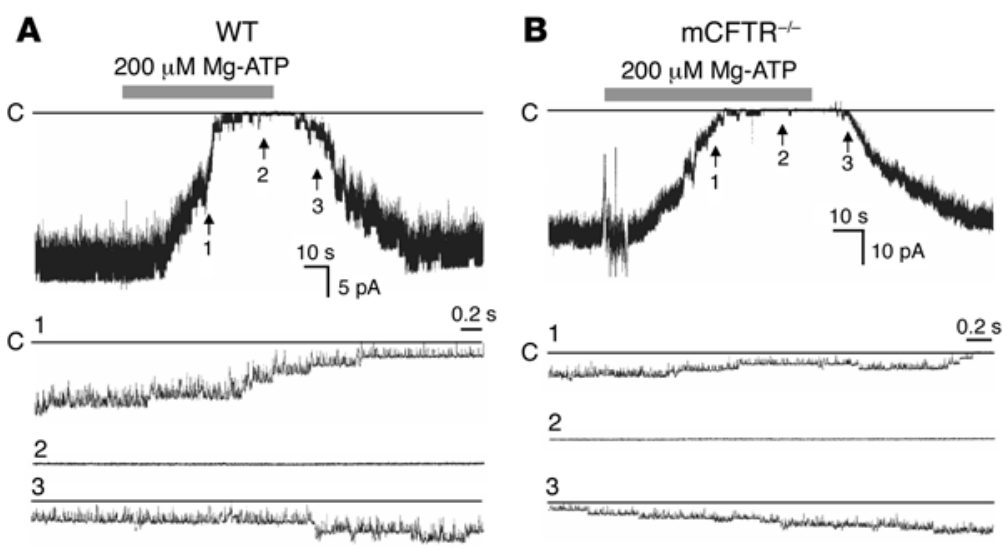

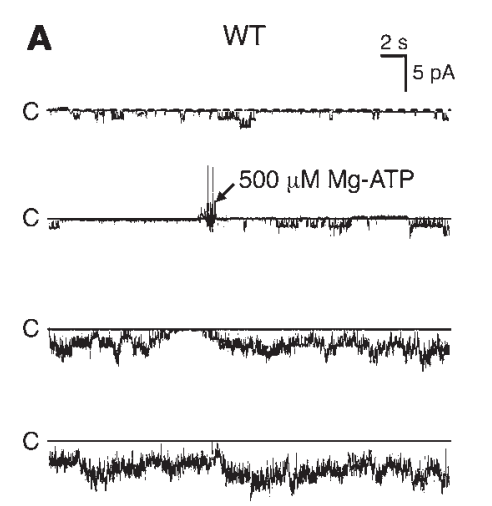

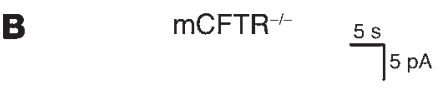

$100 \mu \mathrm{M} M g-A T P$
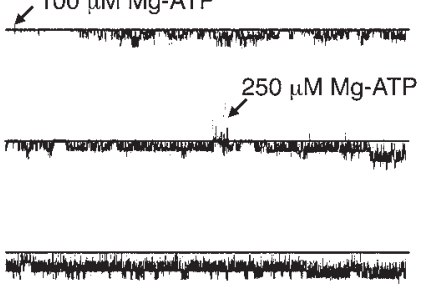

wild-type mouse TAL cell demonstrating that addition of $1 \mathrm{mM}$ Mg-ATP completely inhibited channel activity $\left(N P_{\mathrm{o}}\right.$ decreased from $7.04 \pm 0.16$ to $0.01 \pm 0.04 ; n=5$ ). Channel activity is typically slow to recover (Figure 6A) upon washing into $200 \mu \mathrm{M} \mathrm{Mg-ATP}$ (31). The representative current trace from a $\mathrm{mCFTR}^{-/-}$mouse in Figure 6B shows that ATP sensitivity was dramatically altered. Increases in Mg-ATP up to $8 \mathrm{mM}$ had no significant effect on $N P_{\mathrm{o}}(n=4)$. A Mg-ATP-free, $\mathrm{Ca}^{2+}$-containing Ringers bath solution was used to allow channel rundown to the baseline current $\left(0+\mathrm{Ca}^{2+}\right.$ in Figure $\left.6 \mathrm{~B}\right)$. Following rundown, addition of $1 \mathrm{mM}$ $\mathrm{Mg}$-ATP showed the typical partial recovery (Figure 6B). Figure 6C shows a representative current trace in a TAL cell from a $\triangle F 508$ CFTR mouse illustrating that the Mg-ATP inhibitory effect was also virtually abolished. The Mg-ATP sensitivities for each of the genotypes are compared in Figure 6D. While $2 \mathrm{mM} \mathrm{Mg-ATP}$ completely inhibited $30 \mathrm{pS} \mathrm{K}$ channel activity in wild-type mice (Table 2; Hill coefficient $=4.4 \pm 2.6$ ), $10 \mathrm{mM} \mathrm{Mg-ATP}$ only minimally reduced $N P_{\mathrm{o}}$ from $10.44 \pm 0.23$ to $7.34 \pm 0.31(\sim 32.3 \% ; n=3)$ in mCFTR $^{-/-}$mice and from $8.46 \pm 0.72$ to $6.77 \pm 0.63$ ( $21.4 \%$; $n=3)$ in $\Delta$ F508-CFTR mice. The Mg-ATP IC 50 values were 10.9 $\mathrm{mM}$ (Table 2) for $\mathrm{mCFTR}^{-1-}$ mice and $12.6 \mathrm{mM}$ for $\Delta \mathrm{F} 508$-CFTR mice. Thus, Mg-ATP sensitivity of the $30 \mathrm{pS} \mathrm{K}$ channel required expression of CFTR at the plasma membrane.

Curcumin partially rescues ATP sensitivity of ROMK in $\triangle F 508$-CFTR mice. Curcumin, a constituent of the spice turmeric, exerts complex actions on CFTR function, including both direct and indirect effects. In cultured cells, acute administration of curcumin can act as a CFTR channel opener $(41,42)$ and can reduce PKA-mediated phosphorylation (42). In addition, curcumin is an ER $\mathrm{Ca}^{2+}$-ATPase inhibitor that has been reported to increase plasma membrane expression of $\Delta \mathrm{F} 508$-CFTR in baby hamster kidney cells (43), although this effect on $\triangle$ F508-CFTR trafficking in cultured cells is con-

\section{Figure 5}

Glibenclamide sensitivity of ROMK in inside-out patches from TAL apical membrane of wild-type and $\mathrm{mCFTR}^{-/}$mice. (A) Low concentration of glibenclamide reversibly reduced $\mathrm{ROMK}$ channel activity with an $\mathrm{IC}_{50}$ of $15 \mu \mathrm{M}$ in wild-type mice. (B) Glibenclamide had no significant effect on ROMK channel activity at $0.2 \mathrm{mM}$ $\left(\mathrm{IC}_{50}, 0.68 \mathrm{mM}\right)$ in $\mathrm{mCFTR}^{-1}$ mice. (C) Glibenclamide dose response of the normalized $N P_{0}$.

\section{Figure 4}

Low concentration of cytosolic Mg-ATP stimulated ROMK channels in inside-out patches from TAL apical membrane. Representative continuing recordings show low intracellular Mg-ATP $(100-500 \mu \mathrm{M})$ reactivated ROMK channels following rundown in both wild-type (A) and $\mathrm{mCFTR}^{-1-}$ mice (B).

troversial for this mutant channel (44-47) as well as for other $\mathrm{ABC}$ transporters (47). In $\triangle \mathrm{F} 508$-CFTR mice, both increases (43) and no effects (44) in cAMP-stimulated transepithelial potentials in CFTR-expressing epithelia have been observed.

Curcumin has been suggested to partially recover the defect in CFTR function in $\triangle$ F508-CFTR mice (43). Thus in a subset of $\triangle F 508$-CFTR mice, curcumin was administered orally for 3-7 days, and the ATP sensitivity of the $30 \mathrm{pS} \mathrm{K}$ channel was assessed. Either the rectal potential difference (RPD) and/or the nasal potential difference (NPD) was measured prior to curcumin treatment and at the end of the treatment period $(n=4)$ as described previously (43). In these mice the average baseline NPD after treatment decreased by $12.3 \pm 0.09 \mathrm{mV}$, approaching the baseline values of wild-type mice. In addition, perfusion with the low $\mathrm{Cl}^{-}$solution resulted in a modest hyperpolarization of the NPD similar to that seen in wild-type animals $(4.14 \pm 1.99 \mathrm{mV})$. Finally, perfusion with isoproterenol enhanced this effect further, such that the resultant potential difference was similar to that of wildtype mice $(3.5 \pm 0.91 \mathrm{mV})$. As described previously (43), these data suggest there was a partial correction in the NPD following treatment with curcumin. Similar alterations were observed in the RPD assay in treated mice. As shown in Figure 7A, increases in cytosolic $\mathrm{Mg}-\mathrm{ATP} \geq 6 \mathrm{mM}$ partially inhibited $30 \mathrm{pS} \mathrm{K}$ channel activity in TAL cells from curcumin-treated $\triangle$ F508-CFTR mice. The effect of curcumin is summarized in Figure 7B and shows that this compound restored partial sensitivity to Mg-ATP.

Cytosolic acidification enhances ATP sensitivity of ROMK in the presence and absence of CFTR. Cytosolic $\mathrm{pH}$ is a major regulator of ROMK, with reductions in $\mathrm{pH}$ lowering channel activity (11). In earlier studies, we showed a low intrinsic Mg-ATP sensitivity of ROMK expressed in $X$. laevis oocytes and that this sensitivity could be
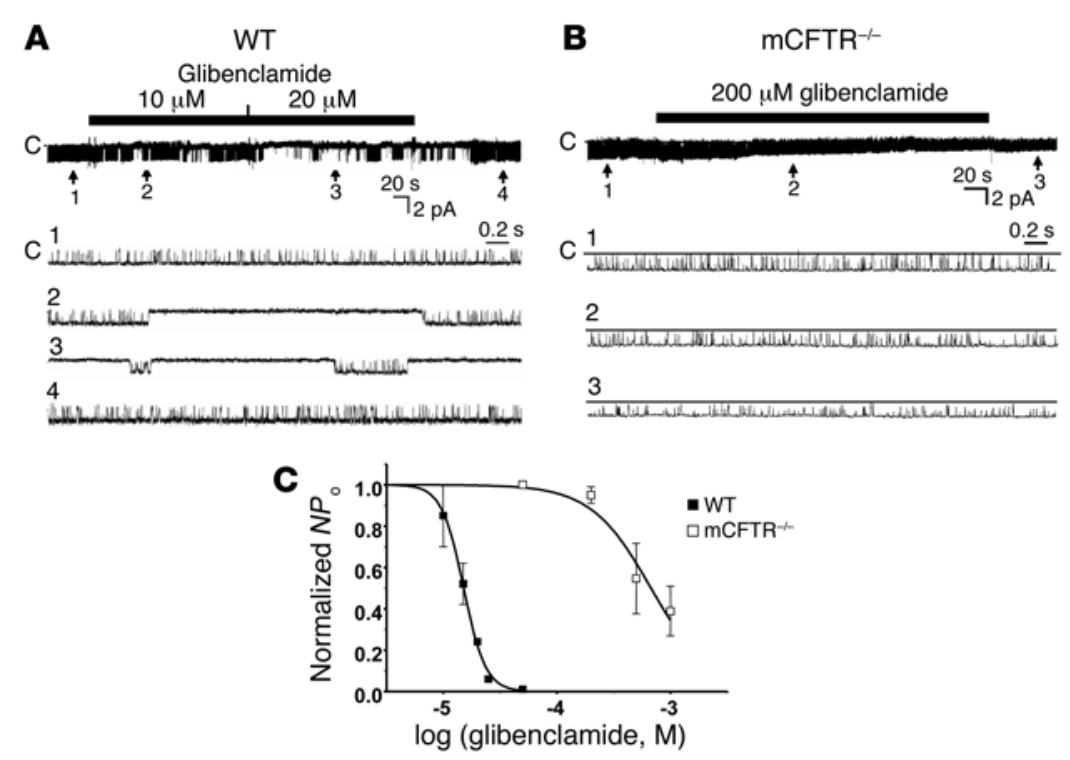

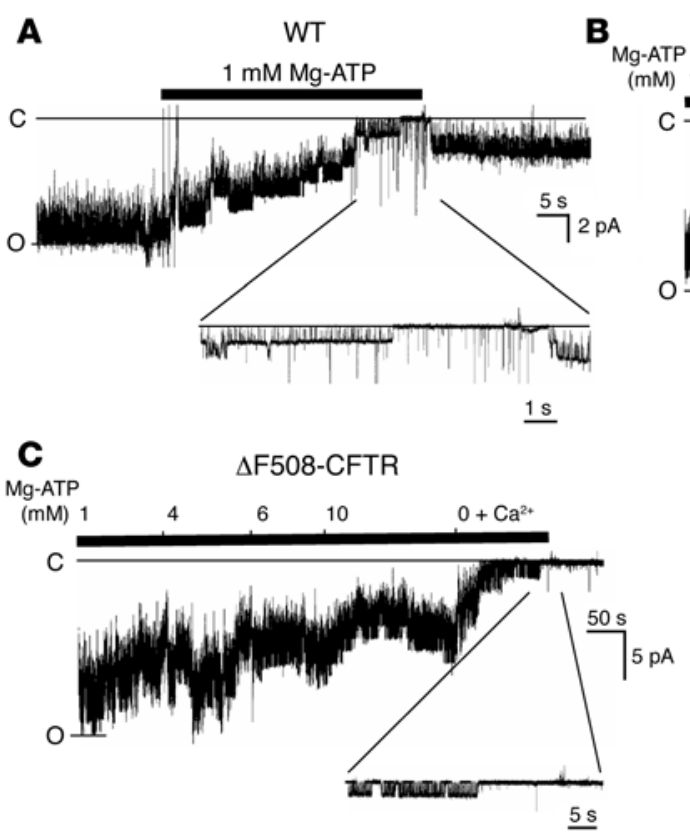

$\underset{\substack{\mathrm{Mg}-\mathrm{ATP} \\(\mathrm{mM})}}{\operatorname{mon}}$

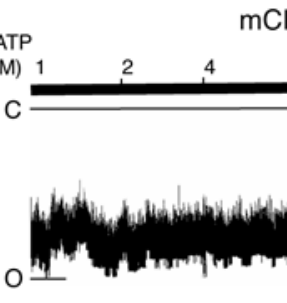

D

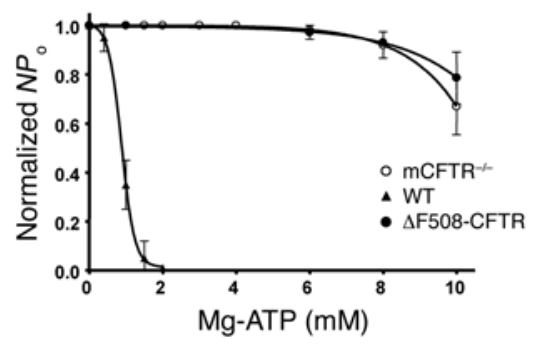

\section{Figure 6}

Effects of Mg-ATP on ROMK channel in inside-out patches from TAL apical membrane. (A) Cytosolic Mg-ATP (1 mM) strongly reduced wild-type ROMK channel activity, which was partially recovered after removing Mg-ATP. However, $10 \mathrm{mM}$ cytosolic MgATP inhibited the ROMK channel activities by only $20-30 \%$ in mCFTR $^{-/-}$(B) and $\triangle$ F508-CFTR (C) mice. Mg-ATP-free and $\mathrm{Ca}^{2+-}$-containing Ringers solution achieved complete channel closure. (D) Mg-ATP dose-response curve of ROMK channel activity determined by normalized $N P_{0}$. enhanced by reducing cytosolic $\mathrm{pH}$ from 7.4 to 7.2 (48). To determine whether lowering cytosolic $\mathrm{pH}$ could also partially restore Mg-ATP sensitivity of $30 \mathrm{pS} \mathrm{K}$ channels in TAL cells in the absence of CFTR, we assessed the effect of lowering intracellular $\mathrm{pH}$ from 7.4 to 7.2 in $\mathrm{mCFTR}^{-/-}$mice (Figure 8 and Table 2 ). Representative currents traces from wild-type and $\mathrm{mCFTR}^{-1-}$ mice are shown in Figure 8, A and B, respectively, and the results are summarized in Figure 8C. In wild-type mice, reduction in cytosolic $\mathrm{pH}$ from 7.4 to 7.2 reduced the $\mathrm{IC}_{50}$ for $\mathrm{Mg}$-ATP from $0.88 \mathrm{mM}$ to $0.61 \mathrm{mM}$ (Table $2 ; n=8)$. In $\mathrm{mCFTR}^{-/-}$mice the same change in $\mathrm{pH}$ produced a dramatic shift of Mg-ATP sensitivity ( $\mathrm{IC}_{50}$ fell from $10.12 \mathrm{mM}$ to 3.22 $\mathrm{mM}$; Table 2; $n=14$ ). Thus, expression of CFTR produced 5 -fold and 10 -fold increases in the sensitivity of ROMK at cytosolic $\mathrm{pH}$ values of 7.4 and 7.2, respectively. This weak intrinsic Mg-ATP sensitivity of the $30 \mathrm{pS} \mathrm{K}$ channel observed in TAL cells in the absence of CFTR is consistent with the ability of the cytosolic regions of ROMK to bind nucleotides $(49,50)$.

Curcumin has recently been reported to alter the channel gating and phosphorylation state of CFTR $(41,42)$ and might therefore affect the gating of other channels. Since many agents or conditions can alter the $\mathrm{pH}$ sensitivity of ROMK and $\mathrm{pH}$ can affect $\mathrm{Mg}$ ATP sensitivity (Table 2; ref. 49), we questioned whether curcumin might alter the $\mathrm{pH}$ gating of ROMK and thereby affect Mg-ATP sensitivity. Indeed, similar effects on ATP sensitivity of cytosolic $\mathrm{pH}$ reduction in $\mathrm{mCFTR}^{-/-}$mice (Figure $8 \mathrm{C}$ ) and curcumin treatment in $\triangle$ F508-CFTR mice (Figure $7 \mathrm{~B}$ ) would be consistent with this possibility. Thus we assessed the acute effects of $10 \mu \mathrm{M}$ curcumin on the ability of $2 \mathrm{mM}$ Mg-ATP to inhibit $30 \mathrm{pS} \mathrm{K}$ channel activity in TAL cells and on the $\mathrm{pH}$ sensitivity of ROMK channels expressed in $X$. laevis oocytes.

Figure 9A shows a representative current trace from an insideout patch of a TAL cell isolated from a wild-type mouse that demonstrates the effects of curcumin on Mg-ATP-mediated inhibition of $30 \mathrm{pS} \mathrm{K}$ channel activity. An approximately 5-minute cytosolic exposure to $10 \mu \mathrm{M}$ curcumin had no effect on channel activity (Figure 9, $\mathrm{A}$ and $\mathrm{B} ; N P_{\mathrm{o}} 7.16 \pm 1.80$ versus $6.98 \pm 1.92$ after curcumin; NS; $n=6$ ). The ability of $2 \mathrm{mM} \mathrm{Mg-ATP}$ to abolish $30 \mathrm{pS} \mathrm{K}$ channel activity in TAL cells was also unaltered (Figure 9, A and B). Figure 9C summarizes the effect of cytosolic $\mathrm{pH}$ on ROMK activity in excised inside-out giant patches from $X$. laevis oocytes $(n=3)$. The $\mathrm{pH}$ sensitivity of ROMK was not altered by extracellular exposure to $10 \mu \mathrm{M}$ curcumin. Thus direct curcumin effects on $30 \mathrm{pS}$ (ROMK) channels did not account for the increase in Mg-ATP sensitivity observed in $\triangle$ F508-CFTR mice following treatment with curcumin (Figure 7).

Enhanced PKA phosphorylation abolishes the inhibitory action of $2 \mathrm{mM}$ cytosolic ATP in TAL and principal cells from wild-type mice. Our previous studies in $X$. laevis oocytes with coexpression of human CFTR and rat ROMK2 showed that forskolin stimulation abolished the sensitivity of ROMK to glibenclamide (21). PKA phosphorylates both $\operatorname{ROMK}(35,36)$ and the regulatory domain of CFTR (51-53), and these phosphorylations activate both channels. Thus, the PKA phosphorylation state of the cell may modulate the functional interactions of CFTR and ROMK.

Since CFTR was required for high sensitivity of ROMK to glibenclamide (Figure 5C) and Mg-ATP (Figure 6D), we examined whether PKA-dependent phosphorylation would also modulate Mg-ATP sensitivity in TAL cells from wild-type mice. Pretreatment of TAL with $2 \mu \mathrm{M}$ forskolin and $300 \mu \mathrm{M}$ 3-isobutyl-1-methylxanthine

Table 2

Channel activity and half inhibition of channel activity by Mg-ATP at bath $\mathrm{pH}$ of 7.2 and 7.4

$\begin{array}{lccc}\text { Genotype } & \mathbf{p H} & \mathbf{N P}_{\mathbf{0}} & \text { IC }_{50} \text { ATP }(\mathbf{m M}) \\ +/+ & 7.4 & 2.22 \pm 0.49 & 0.88 \\ +/+ & 7.2 & 1.15 \pm 0.18 & 0.61 \\ -/- & 7.4 & 5.68 \pm 0.68 & 10.9 \\ -/- & 7.2 & 4.16 \pm 0.51 & 3.2\end{array}$

+/+, wild-type; -/-, CFTR knockout. 


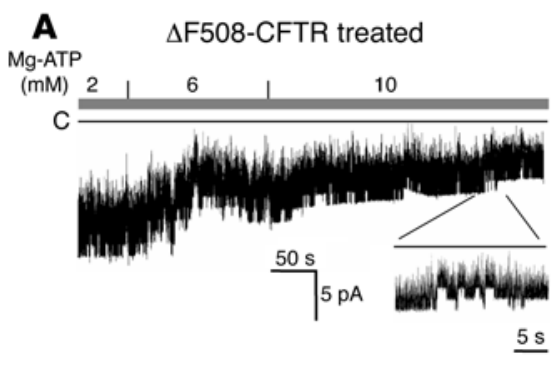

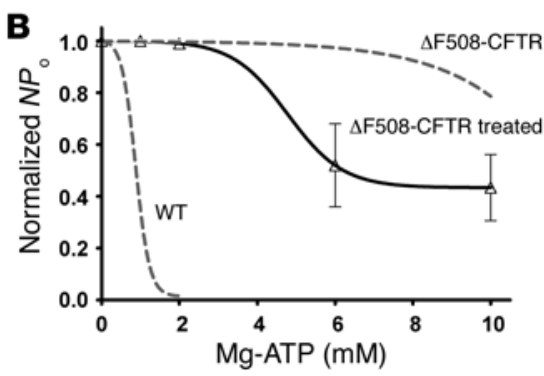

\section{Figure 7}

Oral curcumin treatment of $\Delta$ F508-CFTR mice. (A) Representative single-channel recording shows that $10 \mathrm{mM}$ Mg-ATP inhibited approximately $50 \%$ of channel activity. (B) Mg-ATP dose-response curve of normalized $N P_{0}$. Dotted wild-type and $\Delta$ F508-CFTR curves are from data shown in Figure 6D.
(IBMX) prior to patching abolished the sensitivity of $30 \mathrm{pS}$ channels in TAL cells to $1-2 \mathrm{mM} \mathrm{Mg-ATP} \mathrm{(Figure} \mathrm{10A;} n=3$; compare with Figure 6, A and D).

ROMK is also expressed in principal cells from the CCD, and PKA stimulates $30 \mathrm{pS} \mathrm{K}$ channel activity in these cells (11). Figure $10 \mathrm{C}$ shows a typical current trace from a principal cell, illustrating that $1 \mathrm{mM}$ Mg-ATP reversibly inhibited $\mathrm{K}$ channel activity in a manner similar to the TAL (Figure 6A). Pretreatment of principal cells with forskolin and IBMX also abolished the ability of 1-2 mM Mg-ATP to inhibit channel activity (Figure 10, B and D). Thus, unlike the apparent fixed interaction of Kir6.x subunits with their ABC partners (SUR proteins) in $\mathrm{K}_{\mathrm{ATP}}$ channels $(12,13,26)$, the state of PKA phosphorylation rapidly modulated the functional interaction of ROMK and CFTR with regard to Mg-ATP sensitivity in both TAL and principal cells.

\section{Discussion}

Our results in 2 transgenic mouse models of cystic fibrosis demonstrate that CFTR was necessary for both glibenclamide and Mg-ATP sensitivity of the ROMK-type 30 pS K channel present in TAL cells. Since CFTR and ROMK-type 30 pS K channels were expressed in principal cells of the CCD, the functional interaction between both channels likely also occurs in this renal epithelial cell type. This possibility is supported by the similar effects of PKA phosphorylation on Mg-ATP sensitivity of the K channels we observed in both TAL and principal cells, as shown in Figure 10. However, CFTR had no effect on basic 30 pS K channel properties: single-channel conductance and kinetics, gating by low $\mathrm{pH}$, activation by micromolar Mg-ATP, and inhibition by external ATP via purinergic receptors. Thus, the effect of CFTR on ROMK is apparently specific for gating of the $30 \mathrm{pS} \mathrm{K}$ channel by millimolar cytosolic Mg-ATP.

The functional interaction between CFTR and ROMK is similar to that previously observed for $\mathrm{K}_{\mathrm{ATP}}$ channels, in which another $\mathrm{ABC}$ protein, the sulfonylurea receptor SUR1/2, conferred glibenclamide sensitivity and enhanced ATP interaction with the Kir6.x subunits $(12,13,26)$. These observations suggest a general model for ATP sensitivities of inwardly rectifying $\mathrm{K}$ channels involving $\mathrm{ABC}-\mathrm{Kir}$ interactions. The $\mathrm{ABC}-\mathrm{Kir}$ interactions of CFTR and ROMK are, however, quite distinct from those for classical $K_{A T P}$ channels in 4 respects. First, while $\mathrm{K}_{\mathrm{ATP}}$ channels are formed by a stable 4:4 interaction between SUR1/2 and Kir6.x subunits $(12,13)$, the interaction between CFTR and ROMK may require a third partner. The scaffolding protein NHERF has been shown to stabilize the CFTR-ROMK interaction by binding to both channel proteins via their COOH-terminal PDZ domains $(22,54,55)$. In turn, NHERF can function as a scaffolding protein to link the $30 \mathrm{pS} \mathrm{K}$ channel complex to ezrin, a PKA scaffolding protein $(56,57)$. Second, while SUR1/2-Kir6.x interactions are required for surface expression of $\mathrm{K}_{\mathrm{ATP}}$ channels via mutual shielding of ER retention signals (29),

\section{Figure 8}

Effect of $\mathrm{pH}$ on the Mg-ATP sensitivity of ROMK in inside-out patches from TAL apical membrane of wild-type and mCFTR $^{-1-}$ mice. (A) Representative recordings of the response of single-channel activity to cytosolic Mg-ATP at pH 7.2 in wild-type (A) and $\mathrm{mCFTR}^{-1-}$ (B) mouse inside-out patches. (C) Mg-ATP dose-response curves of channel activity (normalized $N P_{0}$ ) in $\mathrm{mCFTR}^{-1-}$ mice at $\mathrm{pH} 7.2$ and 7.4 (dotted $\mathrm{pH} 7.4$ curve from data shown Figure 6D).

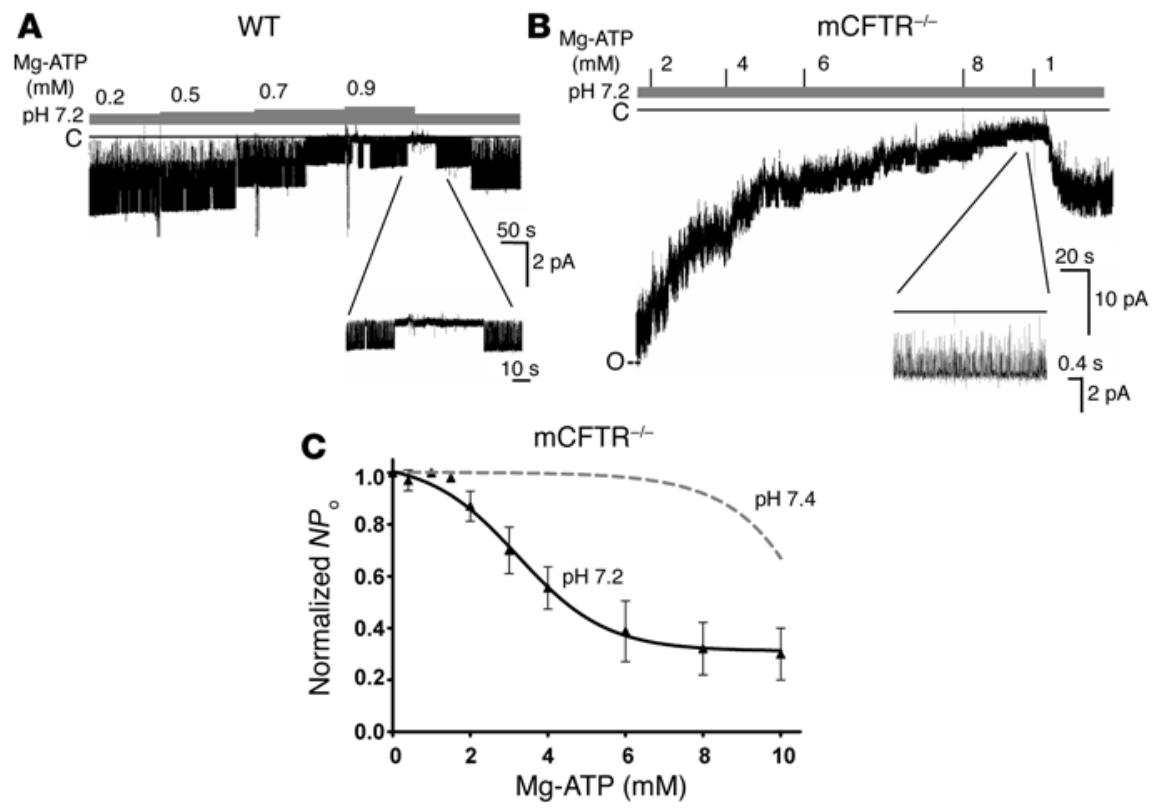



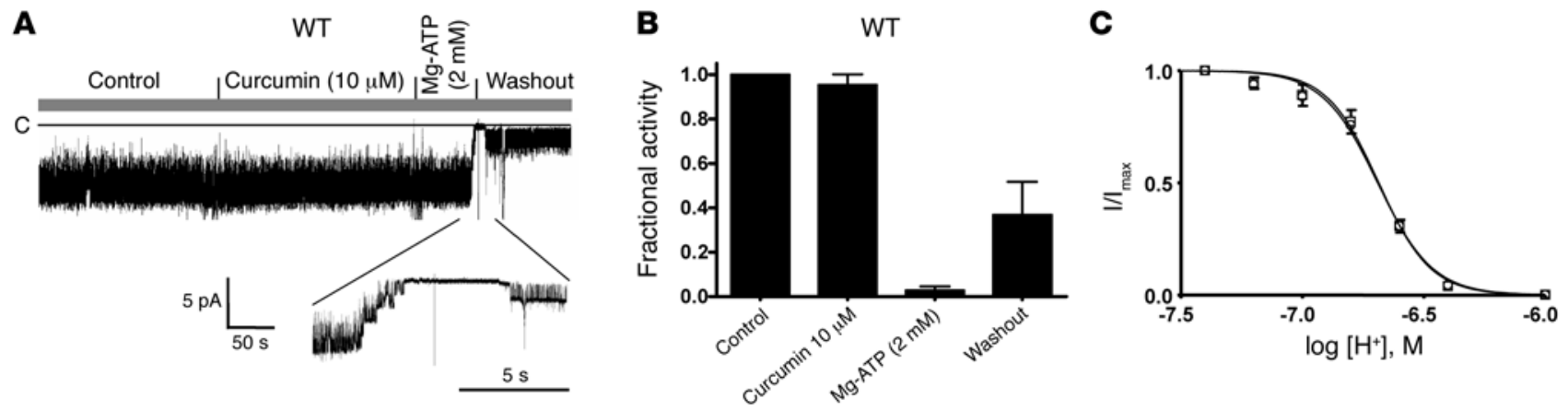

Figure 9

Acute effect of cytosolic curcumin on ROMK in inside-out patches from TAL apical membrane of wild-type mice and in giant patches from $X$. laevis oocytes. (A) Representative single-channel recording of an inside-out patch from wild-type mouse TAL treated with $10 \mu \mathrm{M}$ curcumin. Mg-ATP (2 $\mathrm{mM}$ ) reversibly and completely inhibited channel activity. (B) Average normalized $N P_{\circ}$ after treatment with curcumin and curcumin $+2 \mathrm{mM} M g-$ ATP. (C) pH sensitivity of ROMK in excised inside-out giant patches from $X$. laevis oocytes before (squares) and after exposure (circles) to $10 \mu M$ curcumin ( $\mathrm{pH}$ at $50 \%$ inhibition of current $\left[\mathrm{pH}_{0.5}\right] 6.69 \pm 0.01 ; n=3$ per group). $\mathrm{l} / \mathrm{I}_{\max }$, measured current normalized to maximal current.

CFTR is not required for surface expression of ROMK. The latter was shown by $N P_{\mathrm{o}}$ not being reduced, but rather increased, in $\mathrm{CFTR}^{-/-}$mice (Table 2). Third, the CFTR-ROMK stoichiometry is unknown. SUR1-Kir6.2 exhibits a fixed 4:4 stoichiometry due to mutual shielding of ER retention signals on both Kir6.x and SUR subunits (29). In contrast, ROMK, which also contains a C-terminal ER retention signal, uses a phosphorylation mechanism to promote forward trafficking (58), that is, it does not require interaction with an $\mathrm{ABC}$ protein. However, the Hill coefficients of approximately 4 for glibenclamide and $\mathrm{Mg}$-ATP suggests that the CFTR-ROMK may also be 4:4. Fourth, the functional interaction between CFTR and ROMK was not static as in $\mathrm{K}_{\mathrm{ATP}}$ channels but dynamic, as shown by the abrogation of Mg-ATP sensitivity of the $30 \mathrm{pS} \mathrm{K}$ channels in wild-type mice by increasing the activity of cAMP/PKA (Figure 10). In this regard, Foskett and coworkers (55) have suggested that the magnitude of PKA-stimulated CFTR channel activity is regulated by bivalent PDZ-mediated interactions with NHERF and modulated by the stoichiometry of NHERF/CFTR (54). A recent study (59) supports the dimeric form of CFTR in plasma membranes in cultured cells with a fraction of CFTR dimer formed with NHERF. Thus, it is possible that PKA-mediated activation of CFTR may lead to increased bivalent association of CFTR with NHERF and thereby compete with NHERF-ROMK interactions. The latter would reduce or eliminate CFTR-ROMK interactions critical for Mg-ATP sensitivity.

\section{Figure 10}

Effect of PKA phosphorylation on Mg-ATP sensitivity of ROMK in inside-out patches from TAL and CCD principal cells of wild-type mice. Pretreatment of TAL $(\mathbf{A})$ or principal cells from the CCD (B) with $2 \mu \mathrm{M}$ forskolin and $300 \mu \mathrm{M}$ IBMX prior to patching abolisheed the inhibition of singlechannel activity (normalized $N P_{0}$ ) by 1-2 mM Mg-ATP. (C) Representative recording of the reversible inhibition of ROMK activity by cytosolic $1.2 \mathrm{mM} \mathrm{Mg-ATP}$ in an insideout patch from the apical membrane of a wild-type mouse CCD principal cell. (D) In contrast, following pretreatment with $2 \mu \mathrm{M}$ forskolin and $300 \mu \mathrm{M}$ IBMX, 1-2 mM Mg-ATP had no effect on ROMK activity.
The gating of the $30 \mathrm{pS} \mathrm{K}$ channel by Mg-ATP may be due to interaction of this nucleotide with ROMK and/or CFTR. In the absence of CFTR, weak sensitivity of the $30 \mathrm{pS} \mathrm{K}$ channel to Mg-ATP was observed at the more acidic cytosolic pH of 7.2 (Table 2 and Figure $8 \mathrm{C}$ ), which is the resting $\mathrm{pH}$ of both TAL and principal cells in isolated tubules bathed in $\mathrm{CO}_{2} / \mathrm{HCO}_{3}{ }^{-}$-containing media (60). This suggests that ATP may directly interact with ROMK to gate the channel, a possibility supported by our previous observations that ROMK2 expressed without CFTR in X. laevis oocytes exhibited weak sensitivity to Mg-ATP at a $\mathrm{pH}$ of 7.2 (48) and that proteins containing soluble cytosolic components of ROMK channels can bind TNP-ATP $(49,50)$. Thus, CFTR may enhance the sensitivity of the $30 \mathrm{pS} \mathrm{K}$ channel to ATP by increasing its affinity to bind and gate the channel, a pattern similar to that for $\mathrm{K}_{\text {ATP }}$ channels (61). Alternatively or additionally, the nucleotide binding domains (NBD1 and/or NBD2) on CFTR may provide the critical binding site for gating of ROMK by Mg-ATP. In support of this latter possibility, gating of the $30 \mathrm{pS} \mathrm{K}$ channel in TAL or
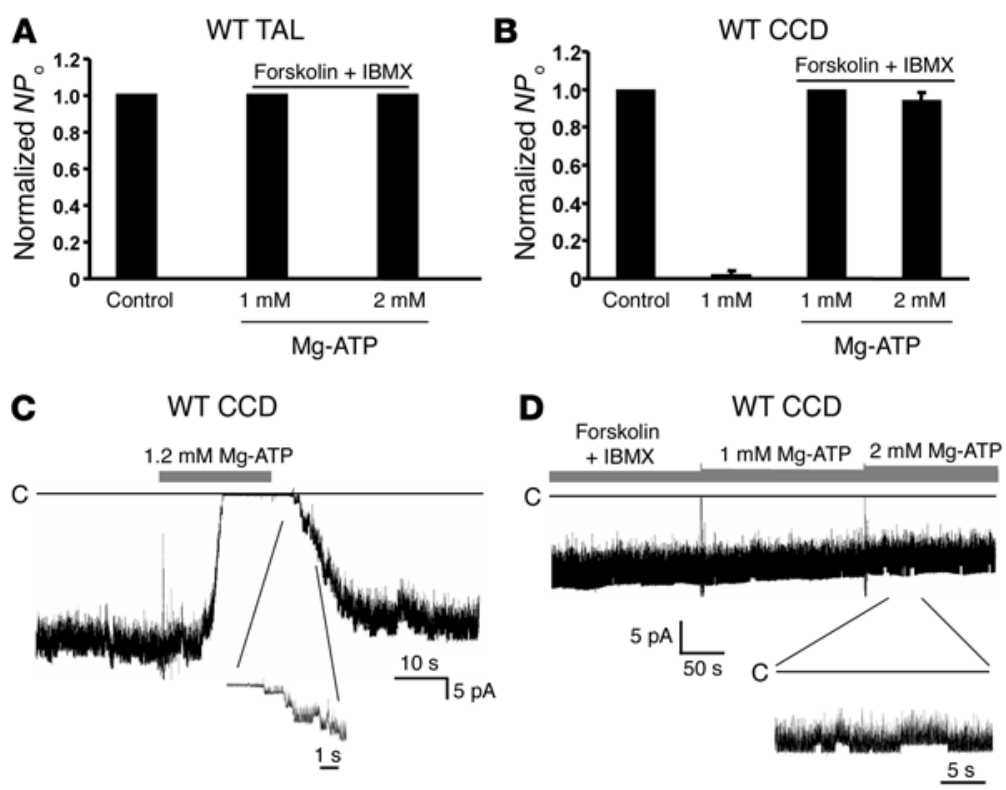
A
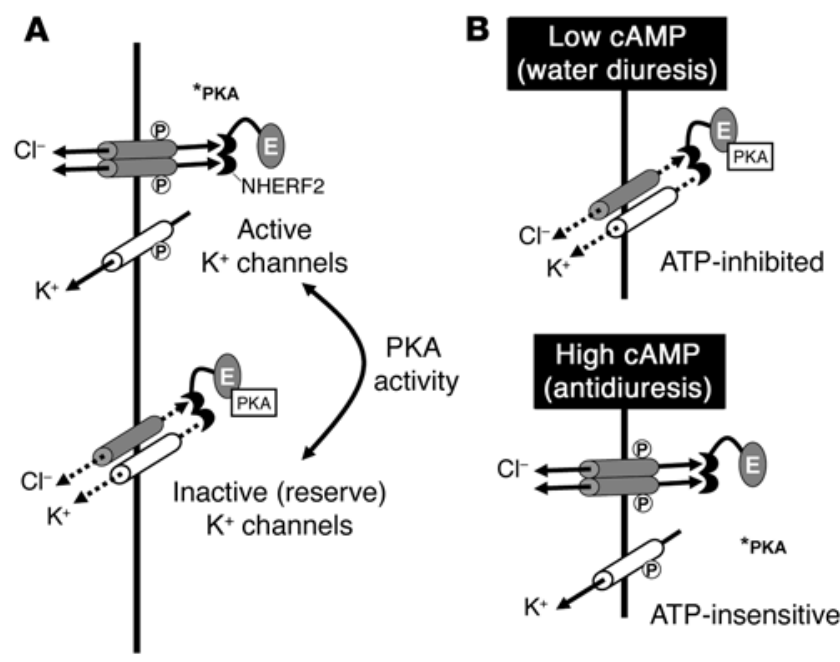

Figure 11

Proposed model for CFTR-ROMK interactions. (A) Two populations of ROMK channels coexist in apical membranes of TAL and principal cells. ROMK channels dissociated from CFTR are insensitive to cytosolic concentrations of ATP and therefore active. The association of ROMK and CFTR may be stabilized by NHERF2, which interacts with ezrin (E), an A kinase anchoring protein (AKAP). ROMK channels in the CFTR-ROMK channel complex is sensitive to normal millimolar ATP and therefore inactive. PKA phosphorylation shifts the channel distribution to the active mode. (B) Phosphorylation of CFTR is a functional switch modulating ROMK channel activity. Low cAMP in water diuresis reduces CFTR phosphorylation allowing CFTR-ROMK interaction and the resultant ATP-inhibition of ROMK averts excessive kaliuresis. High cAMP in antidiuresis phosphorylates CFTR preventing CFTR-ROMK interaction and the resultant lack of ATP-inhibition of ROMK assists kaliuresis. ${ }^{*}$ PKA, active PKA.

principal cells requires $\mathrm{Mg}$-ATP, rather than Na-ATP $(62,63)$, suggesting that ATP hydrolysis may be involved in $\mathrm{K}$ channel gating by nucleotides. Moreover, NBD1 on CFTR has been found to be essential for glibenclamide sensitivity, and by inference for ATP sensitivity (20), of ROMK expressed in $X$. laevis oocytes $(23,24)$.

Curcumin treatment of $\triangle$ F508-CFTR mice (3-7 days) increased the Mg-ATP sensitivity of the $30 \mathrm{pS} \mathrm{K}$ channel in TAL cells. This result is in general agreement with the observations of Egan and coworkers (43) on the ability of oral administration of curcumin in $\triangle F 508$-CFTR mice to partially correct defects associated with homozygous expression of $\Delta \mathrm{F} 508$-CFTR. In contrast, others have failed to rescue abnormal $\Delta \mathrm{F} 508$-CFTR processing in cultured cells or to rescue the functional defects in homozygous $\Delta$ F508-CFTR mice (44). While the reasons for these differences in curcumin effects in $\triangle F 508$-CFTR mice are unclear, the genetic backgrounds of the mice previously used by the Egan (mixed C57b/128; ref. 43) and Verkman (C57b; ref. 44) groups were different which could affect curcumin pharmacokinetics, and thereby responses to this natural product. The dosage, route, and duration of curcumin administration and the $\Delta$ F508-CFTR mice used in the present study were the same as used in the previous study by Egan et al. (43).

Since curcumin had no direct effect on $30 \mathrm{pS}$ or ROMK channel activity or gating, it seems reasonable to suggest that the effect of this treatment on Mg-ATP sensitivity was due to enhanced functional interaction between CFTR and ROMK. The latter could be due to increased availability of $\triangle F 508$-CFTR in the apical mem- branes of TAL cells, to modulation of the functional state of CFTR, or to some other undefined effect. While our experiments did not address which of these possibilities accounted for the effect of curcumin on the ATP sensitivity of the $30 \mathrm{pS}$ K channels, an increase in apical surface availability of $\triangle F 508$-CFTR would be expected to enhance the probability of CFTR-ROMK interactions and thereby Mg-ATP sensitivity. Alternatively, since acute exposure to curcumin has been shown to reduce the phosphorylation state of CFTR (42), it is possible that this could enhance ROMK and $\triangle$ F508-CFTR interactions and thereby increase $\mathrm{Mg}$ ATP sensitivity of the $\mathrm{K}$ channel even in the absence of increased trafficking of the mutant CFTR to the apical membrane. In this regard, we showed that increasing the cAMP/PKA activity in TAL and principal cells abolished the sensitivity of $30 \mathrm{pS} \mathrm{K}$ channels to $2 \mathrm{mM}$ ATP, an observation consistent with our previous studies of $X$ laevis oocytes coexpressing CFTR and ROMK2 (21). Thus, either increased surface delivery of CFTR, altered phosphorylation states of ROMK, CFTR, and/or other associated proteins, or both could account for the increased Mg-ATP sensitivity of the $30 \mathrm{pS} \mathrm{K}$ channel after curcumin treatment.

What is the physiological role of CFTR-ROMK interactions? A functional model incorporating our results is depicted in Figure 11. Two observations suggest this model for CFTR-ROMK interactions: the functional expression of apical $30 \mathrm{pS} \mathrm{K}$ channels was increased in the absence of CFTR (Table 2), and the effect of CFTR on ROMK ATP sensitivity was abrogated by cAMP/PKA (Figure 10). In addition, in vitro experiments suggest that NHERF may stabilize the interaction between CFTR and ROMK (22) and that NHERF interacts with ezrin, which contains a binding site for PKA (57). Accordingly, 2 functional populations of ROMK can exist in apical membranes of TAL and principal cells. ROMK channels associated with CFTR via their respective interactions with NHERF are sensitive to normal millimolar ATP and therefore inactive (Figure 11A). Another fraction of ROMK channels that does not associate with CFTR is insensitive to ATP and is thereby fully active at normal cytosolic concentrations of ATP (Figure 11A). The distribution between inactive and active populations of ROMK is determined by the state of PKA phosphorylation. The model shown in Figure 11 provides a mechanism for rapidly varying the number of functional channels in the apical plasma membrane by PKA-dependent phosphorylation.

In both TAL and principal cells of the CCD, the peptide hormone arginine vasopressin (AVP, or antidiuretic hormone), is a major regulator of cell cAMP and therefore PKA activity. AVP was shown to increase the $\mathrm{Ba}^{2+}$-sensitive apical $\mathrm{K}$ conductance of mouse TAL (65), and in the rat this hormone increased fractional $\mathrm{K}$ excretion by $77 \%$ despite a 7 -fold reduction in urine flow rate (66). In addition, in the rat $\mathrm{AVP}$ increased the $N P_{\mathrm{o}}$ of small-conductance $K$ channels in principal cells from the CCD (66) and enhanced the $\mathrm{Ba}^{2+}$-sensitive $\mathrm{Rb}$ flux from bath to lumen in the isolated perfused CCD (67). Although the driving force for K secretion in TAL and CCD may be modified by exposure to AVP under certain conditions (68), it is clear that apical $30 \mathrm{pS} \mathrm{K}$ channel activity is increased following exposure to this cAMP-generating hormone.

What are the physiological implications of this model for renal potassium handling? In the water diuretic state, when AVP levels are low, CFTR and ROMK interact, producing a functional complex wherein ROMK is highly sensitive to cell ATP and the $30 \mathrm{pS}$ $\mathrm{K}$ channels would therefore be inactive (low cAMP; Figure 11B). In contrast, in the antidiuretic state, when AVP is high, CFTR no lon- 
ger interacts with ROMK, and the $30 \mathrm{pS} \mathrm{K}$ channel is insensitive to cytosolic ATP and therefore fully active (high cAMP; Figure 11B). Thus CFTR acts as a functional switch that modulates $\mathrm{K}$ channel activity between the water diuretic and antidiuretic states. In the water diuretic state, when urinary flow is high, the reduced apical $\mathrm{K}$ conductance would limit $\mathrm{K}$ secretion and urinary $\mathrm{K}$ loss. In contrast, in cystic fibrosis, when plasma membrane CFTR is absent, $\mathrm{K}$ secretion would be maintained during water diuresis, leading to increased urinary $\mathrm{K}$ loss. Consistent with this notion, individuals with cystic fibrosis may be more prone to the development of hypokalemic metabolic alkalosis $(69,70)$.

\section{Methods}

CFTR transgenic mice. The cftrtm1Unc-cftr ${ }^{\text {hFABP }}$ transgenic mouse (mCFTR-/-; ref. 27) lacks expression of mouse CFTR but expresses human CFTR, which is driven by the intestinal specific promoter for the rat fatty acid binding protein (FABP). This rescues the severe gastrointestinal phenotype of the $c f r^{t m 1 U n c}$ mouse $(27,71)$. We also used the $c f r^{t m 1 K t h}$ transgenic mouse $(28,43)$, in which CFTR contains the $\Delta$ F508 mutation $(\Delta F 508$-CFTR), on a mixed genetic background (approximately 25\% 129 and 75\% C57BL/6). The $\Delta$ F508-CFTR transgenic mice have a high mortality and demonstrate poor weight gain due to abnormal intestinal function. To improve survival, all mice were fed with Harlan Teklad 9F food and drinking water that was supplemented with $17.5 \mathrm{~g} / 250 \mathrm{ml}$ of Colyte (SCHWARZ PHARMA). In both CFTR transgenic mouse models, mouse CFTR expression in kidney is absent. C57BL/6 mice (20-30 g, Charles River Laboratories) were used as wild-type controls for ROMK and CFTR channel activity and were fed standard mouse chow. All mice were maintained at the Yale University Animal Facility and were genotyped with standard protocols. All procedures were performed in compliance with relevant laws and institutional guidelines and were approved by the Yale University Institutional Animal Care and Use Committee.

Curcumin treatment. The $\Delta$ F508-CFTR mice were treated with orally administered curcumin at $45 \mathrm{mg} / \mathrm{kg}$ daily for 3-7 days. Curcumin powder was mixed into liquid formula (Alimentim; Ross Laboratories), and the suspension was fed to the animals via direct pipetting into the mouth as a divided dose 3 times daily.

NPD. The NPD of the mice was measured using a high-impedance voltmeter as previously described (43). The measurement was performed twice on each mouse, once before treatment and another after treatment. Briefly, a probing bridge - PE10 tubing pulled to a diameter of 3-5 microns and perfused with various saline solutions - was placed into a nostril of the mouse. A reference electrode (27-gauge butterfly needle filled with $4 \%$ agar in Ringers solution) was placed subcutaneously. A microperfusion pump controlled the saline flow through the probing electrode $(0.15 \mathrm{ml} / \mathrm{h})$. During the procedure the mice were maintained on a warming pad, and saline drops were used to keep their eyes moist. Since there is some discomfort with the procedure, the mice were anesthetized with ketamine $(100 \mathrm{mg} / \mathrm{kg}$; and Xylazine, $10 \mathrm{mg} / \mathrm{ml}$ i.p.). They were continually observed throughout the procedure as well as after until they fully recovered.

$R P D$. RPD was measured with a protocol similar to that used in NPD and as previously described by Egan et al. (43). Briefly, a probing bridge - PE10 tubing perfused with various saline solutions - was inserted $1-2 \mathrm{~cm}$ into the rectum of the mouse. A reference electrode (27-gauge butterfly needle filled with 4\% agar in Ringers solution) was placed subcutaneously. A microperfusion pump controlled the saline flow through the probing electrode $(0.3 \mathrm{ml} / \mathrm{h})$. Mice were anesthetized as above. Mice were continually observed throughout the procedure as well as after until they fully recovered.

Preparation and patch clamping of kidney tubules. Transverse kidney slices were cut and placed in chilled dissection solution, and cortical TAL or cortical collecting tubules were dissected under microscope at room temperature with forceps. The individual tubules were immobilized on a $5-\mathrm{mm} \times 5-\mathrm{mm}$ cover glass coated with Cell-Tak (Biopolymers) and transferred to a chamber mounted on the stage of an inverted microscope (Olympus IMT-2). The tubules were opened lengthwise with a sharpened micropipette to expose the luminal surface of the cells, and patch clamping was carried out at room temperature $\left(22-24^{\circ} \mathrm{C}\right)$. Tubules were dissected and bathed in Ringers solution containing $140 \mathrm{mM} \mathrm{NaCl}, 5 \mathrm{KCl}, 1.8 \mathrm{mM} \mathrm{MgCl}_{2}, 1.8 \mathrm{mM} \mathrm{CaCl}_{2}$, and $10 \mathrm{mM}$ HEPES and adjusted to $\mathrm{pH} 7.4$ or 7.2 with $\mathrm{NaOH}$. Glass pipettes were pulled from borosilicate glass capillaries (Dagan Corporation) using a 2-step Narishige PP83 puller (Narishige Scientific Instrument Lab). Pipette tips were polished with Narishige MF-83, and the pipette resistance ranged from 6 to $8 \mathrm{M} \Omega$ when filled with $140 \mathrm{mM} \mathrm{KCl}$ pipette solution. The pipette contained $140 \mathrm{mM} \mathrm{KCl}, 1.8 \mathrm{mM} \mathrm{MgCl}_{2}$, and $10 \mathrm{mM}$ HEPES and was adjusted to $\mathrm{pH} 7.4$ with $\mathrm{KOH}$. When patches were excised, the bath solution was replaced with a $\mathrm{Ca}^{2+}$-free bath solution containing $140 \mathrm{mM} \mathrm{NaCl}, 5 \mathrm{mM}$ $\mathrm{KCl}, 1.8 \mathrm{mM} \mathrm{MgCl}_{2}, 2 \mathrm{mM}$ EDTA, $10 \mathrm{mM}$ HEPES, and $0.2 \mathrm{mM} \mathrm{Mg}$-ATP to prevent channel rundown and adjusted to $\mathrm{pH} 7.4$ with $\mathrm{NaOH}$.

Preparation and patch clamping of X. laevis oocytes. Frogs were anesthetized in $0.02 \% 3$-aminobenzoic acid ethyl ester (tricaine titrated to $\mathrm{pH} 7.4$ with $5 \mathrm{mM}$ Hepes using $\mathrm{NaOH}$ ) for 3-7 minutes. After partial ovariectomy, oocytes were defolliculated in a $\mathrm{Ca}^{2+}$-free solution $(96 \mathrm{mM} \mathrm{NaCl}, 2 \mathrm{mM}$ $\mathrm{KCl}, 2 \mathrm{mM} \mathrm{MgCl}_{2}$, and $5 \mathrm{mM}$ HEPES, adjusted to $\mathrm{pH} 7.4$ with $\mathrm{NaOH}$ ) containing $2 \mathrm{mg} / \mathrm{ml}$ type $1 \mathrm{~A}$ collagenase (Sigma-Aldrich). Oocytes were washed and kept in ND-96 solution $(96 \mathrm{mM} \mathrm{NaCl}, 2 \mathrm{mM} \mathrm{KCl}, 1 \mathrm{mM}$ $\mathrm{MgCl}_{2}, 1.8 \mathrm{mM} \mathrm{CaCl}_{2}$, and $5 \mathrm{mM}$ HEPES, adjusted to $\mathrm{pH} 7.4$ with $\mathrm{NaOH}$ ) for injection. ROMK2 cDNA was subcloned into pSPORT-1 vectors and linearized with Not-1 restriction endonuclease to generate full-length complementary RNA (cRNA) transcripts. Oocytes were injected with $50 \mathrm{nl}$ of cRNA (5 ng) or water (control) using an Inject + Matic (Geneva) injector no later than 12 hours after defolliculation. Oocytes were then incubated in ND-96 solution containing $500 \mathrm{U} / \mathrm{ml}$ penicillin and $500 \mu \mathrm{g} / \mathrm{ml}$ streptomycin (Invitrogen Corp.) at $18^{\circ} \mathrm{C}$ for 48 hours. Before patch clamping oocytes, the vitelline membrane was removed with a forceps following immersion in a hyperosmotic solution for 1-2 minutes (200 mM $N$-methyl-D-glucamine, $2 \mathrm{mM} \mathrm{KCl}, 1 \mathrm{mM} \mathrm{MgCl}_{2}, 10 \mathrm{mM}$ EGTA, and $10 \mathrm{mM}$ HEPES, adjusted to $\mathrm{pH}$ 7.4 with $\mathrm{HCl}$ ). Oocyte bath solution contained $150 \mathrm{mM} \mathrm{KCl}, 2 \mathrm{mM}$ EDTA, and $10 \mathrm{mM} \mathrm{Mes/Tris} \mathrm{and} \mathrm{was} \mathrm{adjusted} \mathrm{to} \mathrm{pH} 7.4,7.2,7.0,6.8,6.6,6.4$, or 6.0. Macropatch electrodes were filled with $150 \mathrm{mM} \mathrm{KCl,} 1 \mathrm{mM} \mathrm{MgCl}$, $1 \mathrm{mM} \mathrm{CaCl}_{2}$, and $5 \mathrm{mM} \mathrm{Mes/Tris} \mathrm{and} \mathrm{adjusted} \mathrm{to} \mathrm{pH} 7.4$ with Mes or Tris buffer. A multibarreled quick-exchange solution system (model SF-77B; Warner Instruments) was used in oocyte giant patches. Glibenclamide, Mg-ATP, forskolin, and IBMX were purchased from Sigma-Aldrich. Curcumin (Sigma-Aldrich) stock solution was solved in DMSO. The final concentration of DMSO in the experimental solution was less than 1:1,000, which has no effect on channel activity. All the experimental solutions were made freshly on the day of experiment.

Statistics. Single-channel currents were amplified by an EPC-7 amplifier (List Electronics) and low-pass filtered at $1 \mathrm{kHz}$ by an 8-pole Bessel filter (902LPF; Frequency Devices). Signals were digitized at a sampling rate $4 \mathrm{kHz}$ (DigiData 1200; Axon Instruments) and saved in a PC for future analysis. Patch data were analyzed using PCLAMP software (version 6.0.4; Axon Instruments) at a digital filter frequency of $500 \mathrm{~Hz}$. Channel activity was calculated by the following equation during sampling periods of 10-30 seconds.

\section{Equation 1

$$
N P_{0}=\Sigma\left(t_{1}+t_{2}+\ldots t_{n}\right)
$$

where $N$ is the number of observed current levels in the patch, $\mathrm{P}_{\mathrm{o}}$ is the single-channel open probability, and $t_{\mathrm{n}}$ is the fractional open time spent 
at each of the current levels. Results are given as means \pm SEM. Statistical significance was determined using 2-tailed Student's $t$ test; a $P$ value less than 0.05 was considered significant. Channel conductance was estimated from linear regression analysis of single-channel current-voltage curves. Voltage applied to the pipette was referenced to the bath potential; holding potential $(-\mathrm{V})$ was $-40 \mathrm{mV}$ unless indicated otherwise in the figures.

\section{Acknowledgments}

This work was supported by NIH grants DK17433 (to S.C. Hebert and E.L. Boulpaep), DK054999 (to S.C. Hebert), and DK53428 (to M.E. Egan) and a Postdoctoral Fellowship grant from the Ameri- can Heart Association (0425865T; to Q. Leng). We thank William

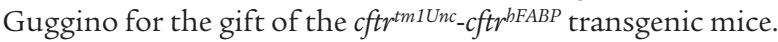

Received for publication September 26, 2005, and accepted in revised form November 29, 2005.

Address correspondence to: Steven C. Hebert, Department of Cellular and Molecular Physiology and Medicine, Yale University School of Medicine, 333 Cedar Street, PO Box 208026, New Haven, Connecticut 06520-8026, USA. Phone: (203) 785-4041; Fax: (203) 785-7678; E-mail: steven.hebert@yale.edu.
1. Sheppard, D.N., and Welsh, M.J. 1999. Structure and function of the CFTR chloride channel. Physiol. Rev. 79:S23-S45.

2. Stanton, B.A. 1997. Cystic fibrosis transmembrane conductance regulator (CFTR) and renal function. Wien. Klin. Wochenschr. 109:457-464.

3. Devuyst, O., Burrow, C.R., Schwiebert, E.M., Guggino, W.B., and Wilson, P.D. 1996. Developmental regulation of CFTR expression during human nephrogenesis. Am. J. Physiol. 271:F723-F735.

4. Morales, M.M., et al. 1996. Both the wild type and a functional isoform of CFTR are expressed in kidney. Am. J. Physiol. Renal Physiol. 270:F1038-F1048.

5. Crawford, I., et al. 1991. Immunocytochemical localization of the cystic fibrosis gene product CFTR. Proc. Natl. Acad. Sci. U. S. A. 88:9262-9266.

6. Riordan, J.R., et al. 1989. Identification of the cystic fibrosis gene: cloning and characterization of complementary DNA. Science. 245:1066-1073.

7. Devuyst, O., and Guggino, W.B. 2002. Chloride channels in the kidney: lessons learned from knockout animals. Am. J. Physiol. Renal Physiol. 283:F1176-F1191.

8. Ho, K., et al. 1993. Cloning and expression of an inwardly rectifying ATP-regulated potassium channel. Nature. 362:31-38.

9. Kunzelmann, K. 2001. CFTR: interacting with everything? News Physiol. Sci. 16:167-170.

10. Schwiebert, E.M., Benos, D.J., Egan, M., Stutts, M.J., and Guggino, W.B. 1999. CFTR is a conductance regulator as well as a chloride channel. Physiol. Rev. 79:S145-S166.

11. Hebert, S.C., Desir, G., Giebisch, G., and Wang, W. 2005. Molecular diversity and regulation of renal potassium channels. Physiol. Rev. 85:319-371.

12. Tucker, S.J., and Ashcroft, F.M. 1998. A touching case of channel regulation: the ATP-sensitive $\mathrm{K}^{+}$ channel. Curr. Opin. Neurobiol. 8:316-320.

13. Aguilar-Bryan, L., et al. 1998. Toward understanding the assembly and structure of $\mathrm{K}_{\mathrm{ATP}}$ channels. Physiol. Rev. 78:227-245.

14. Karolyil, L., et al. 1997. Mutations in the gene encoding the inwardly-rectifying renal potassium channel, ROMK, cause the antenatal variant of Bartter syndrome: evidence for genetic heterogeneity. Hum. Mol. Genet. 6:17-26.

15. Simon, D.B., et al. 1996. Genetic heterogeneity of Bartter's syndrome revealed by mutations in the $\mathrm{K}^{+}$ channel, ROMK. Nat. Genet.14:152-156.

16. Lorenz, J.N., et al. 2002. Impaired renal $\mathrm{NaCl}$ absorption in mice lacking the ROMK potassium channel, a model for type II Bartter's syndrome. J. Biol. Chem. 277:37871-37880.

17. Lu, M., et al. 2002. Absence of small-conductance $\mathrm{K}^{+}$channel (SK) activity in apical membranes of thick ascending limb and cortical collecting duct in ROMK (Bartter's) knockout mice. J. Biol. Chem. 277:37881-37887.

18. Lu, M., et al. 2004. ROMK is required for expression of the $70 \mathrm{pS} \mathrm{K}$ channel in the thick ascending limb. Am. J. Physiol. Renal Physiol. 286:F490-F495.

19. Wang, T., Wang, W.-H., Klein-Robbenhaar, G., and Giebisch, G. 1995. Effects of glyburide on renal tubule transport and potassium-channel activity. Ren. Physiol. Biochem. 18:169-182.

20. Ruknudin, A., Schulze, D.H., Sullivan, S.K., Lederer, W.J., and Welling, P.A. 1998. Novel subunit composition of a renal epithelial $\mathrm{K}_{\mathrm{ATP}}$ channel. J. Biol. Chem. 273:14165-14171.

21. McNicholas, C.M., et al. 1996. Sensitivity of a renal $\mathrm{K}^{+}$channel (ROMK2) to the inhibitory sulfonylurea compound, glibenclamide, is enhanced by co-expression with the ATP-binding cassette transporter cystic fibrosis transmembrane regulator. Proc. Natl. Acad. Sci. U. S. A. 93:8083-8088.

22. Yoo, D., et al. 2004. Assembly and trafficking of a multiprotein ROMK (Kir1.1) channel complex by PDZ interactions. J. Biol. Chem. 279:6863-6873.

23. McNicholas, C.M., et al. 1997. A functional CFTRNBF1 is required for ROMK2-CFTR interaction. Am. J. Physiol. Renal Physiol. 273:F843-F848.

24. Cahill, P., et al. 2000. Identification of the cystic fibrosis transmembrane conductance regulator domains that are important for interactions with ROMK2. J. Biol. Chem. 275:16697-16701.

25. Tanemoto, M., et al. 2000. Rat homolog of sulfonylurea receptor $2 \mathrm{~B}$ determines glibenclamide sensitivity of ROMK2 in Xenopus laevis oocyte. Am. J. Physiol. Renal Physiol. 278:F659-F666.

26. Inagaki, N., et al. 1995. Reconstitution of $\mathrm{I}_{\mathrm{ATP}}$ : an inward rectifier subunit plus the sulfonylurea receptor. Science. 270:1166-1170.

27. Zhou, L., et al. 1994. Correction of lethal intestinal defect in a mouse model of cystic fibrosis by human CFTR. Science. 266:1705-1708.

28. Zeiher, B.G., et al. 1995. A mouse model for the $\delta$ F508 allele of cystic fibrosis. J. Clin. Invest. 96:2051-2064.

29. Zerangue, N., Schwappach, B., Jan, Y.N., and Jan, L.Y. 1999. A new ER trafficking signal regulates the subunit stoichiometry of plasma membrane $\mathrm{K}_{\mathrm{ATP}}$ channels. Neuron. 22:537-548.

30. Unwin, R.J., Bailey, M.A., and Burnstock, G. 2003. Purinergic signaling along the renal tubule: the current state of play. News Physiol. Sci. 18:237-241.

31. Lu, M., MacGregor, G.G., Wang, W., and Giebisch, G. 2000. Extracellular ATP inhibits the small-conductance $\mathrm{K}$ channel on the apical membrane of the cortical collecting duct from mouse kidney. J. Gen. Physiol. 116:299-310.

32. Devidas, S., and Guggino, W.B. 1997. The cystic fibrosis transmembrane conductance regulator and ATP. Curr. Opin. Cell Biol. 9:547-552.

33. Egan, M.E. 2002. CFTR-associated ATP transport and release. Methods Mol. Med. 70:395-406.

34. Reisin, I.L., et al. 1994. The cystic fibrosis transmembrane conductance regulator is a dual ATP and chloride channel. J. Biol. Chem. 269:20584-20591.

35. Xu, Z.C., Yang, Y., and Hebert, S.C. 1996. Phosphorylation of the ATP-sensitive, inwardly rectifying $\mathrm{K}^{+}$channel, ROMK, by cyclic AMP-dependent protein kinase. J. Biol. Chem. 271:9313-9319.

36. MacGregor, G.G., Xu, J., McNicholas, C.M., Giebisch, G., and Hebert, S.C. 1998. Partially active channels produced by PKA site mutation of the cloned renal $\mathrm{K}^{+}$channel ROMK2. Am. J. Physiol.
Renal Physiol. 275:F415-F422.

37. Lu, M., Hebert, S.C., and Giebisch, G. 2002. Hydrolyzable ATP and PIP(2) modulate the small-conductance $\mathrm{K}(+)$ channel in apical membranes of rat cortical-collecting duct (CCD). J. Gen. Physiol. 120:603-615.

38. Huang, C.-L., Feng, S., and Hilgemann, D.W. 1998. Direct activation of inward rectifier potassium channels by $\mathrm{PIP}_{2}$ and its stabilization by G $\beta \gamma$. Nature. 391:803-806.

39. Liou, H.H., Zhou, S.S., and Huang, C.L. 1999. Regulation of ROMK1 channel by protein kinase A via a phosphatidylinositol 4,5-bisphosphatedependent mechanism. Proc. Natl. Acad. Sci. U. S. A. 96:5820-5825

40. Wang, W.H., White, S., Geibel, J., and Giebisch, G. 1990. A potassium channel in the apical membrane of rabbit thick ascending limb of Henle's loop. Am. J. Physiol. 258:F244-F253.

41. Wang, W., Li, G., Clancy, J.P., and Kirk, K.L. 2005. Activating CFTR channels with pore blocker analogs. J. Biol. Chem. 280:23622-23630.

42. Berger, A.L., et al. 2005. Curcumin stimulates cystic fibrosis transmembrane conductance regulator $\mathrm{Cl}^{-}$channel activity. J. Biol. Chem. 280:5221-5226.

43. Egan, M.E., et al. 2004. Curcumin, a major constituent of turmeric, corrects cystic fibrosis defects. Science. 304:600-602.

44. Song, Y., et al. 2004. Evidence against the rescue of defective DeltaF508-CFTR cellular processing by curcumin in cell culture and mouse models. J. Biol. Chem. 279:40629-40633.

45. Dragomir, A., Bjorstad, J., Hjelte, L., and Roomans, G.M. 2004. Curcumin does not stimulate cAMPmediated chloride transport in cystic fibrosis airway epithelial cells. Biochem. Biophys. Res. Commun. 322:447-451.

46. Mall, M., and Kunzelmann, K. 2005. Correction of the CF defect by curcumin: hypes and disappointments. Bioessays. 27:9-13.

47. Loo, T.W., Bartlett, M.C., and Clarke, D.M. 2004 Thapsigargin or curcumin does not promote maturation of processing mutants of the $\mathrm{ABC}$ transporters, CFTR, and P-glycoprotein. Biochem. Biophys. Res. Commun. 325:580-585.

48. McNicholas, C.M., et al. 1998. pH-dependent modulation of the cloned renal $\mathrm{K}^{+}$channel, ROMK. Am. J. Physiol. Renal Physiol. 275:F972-F981.

49. Dong, K., Tang, L., MacGregor, G.G., Leng, Q., and Hebert, S.C. 2005. Novel nucleotide-binding sites in ATP-sensitive potassium channels formed at gating interfaces. EMBO J. 24:1318-1329.

50. Vanoye, C.G., et al. 2002. The carboxyl termini of $\mathrm{K}_{\mathrm{ATP}}$ channels bind nucleotides. J. Biol. Chem. 277:23260-23270.

51. Gadsby, D.C., and Nairn, A.C. 1999. Control of CFTR channel gating by phosphorylation and nucleotide hydrolysis. Physiol. Rev. 79:S77-S107.

52. Berger, H.A., et al. 1991. Identification and regulation of the cystic fibrosis transmembrane conductance regulator-generated chloride channel. J. Clin. Invest. 88:1422-1431.

53. Tabcharani, J.A., Chang, X.B., Riordan, J.R., and 
Hanrahan, J.W. 1991. Phosphorylation-regulated $\mathrm{Cl}^{-}$channel in $\mathrm{CHO}$ cells stably expressing the cystic fibrosis gene. Nature. 352:628-631.

54. Ladias, J.A. 2003. Structural insights into the CFTRNHERF interaction. J. Membr. Biol. 192:79-88.

55. Raghuram, V., Mak, D.D., and Foskett, J.K. 2001. Regulation of cystic fibrosis transmembrane conductance regulator single-channel gating by bivalent PDZ-domain-mediated interaction. Proc. Natl. Acad. Sci. U. S. A. 98:1300-1305.

56. Dransfield, D.T., et al. 1997. Ezrin is a cyclic AMPdependent protein kinase anchoring protein. EMBO J. 16:35-43.

57. Sun, F., et al. 2000. E3KARP mediates the association of ezrin and protein kinase A with the cystic fibrosis transmembrane conductance regulator in airway cells. J. Biol. Chem. 275:29539-29546.

58. O'Connell, A.D., et al. 2005. Phosphorylation regulated ER retention signal in the ROMK potassium channel. Proc. Natl. Acad. Sci. U. S. A. 102:9954-9959.

59. Li, C., Roy, K., Dandridge, K., and Naren, A.P. 2004. Molecular assembly of cystic fibrosis transmembrane conductance regulator in plasma membrane. J. Biol. Chem. 279:24673-24684.
60. Hebert, S.C. 1986. Hypertonic cell volume regulation in mouse thick limbs II. $\mathrm{Na}^{+}-\mathrm{H}^{+}$and $\mathrm{Cl}^{-}-\mathrm{HCO}_{3}^{-}$ exchange in basolateral membranes. Am. J. Physiol. Cell Pbysiol. 250:C920-C931.

61. Tucker, S.J., et al. 1998. Molecular determinants of $\mathrm{K}_{\mathrm{ATP}}$ channel inhibition by ATP. EMBO J. 17:3290-3296

62. McNicholas, C.M., Yang, Y., Giebisch, G., and Hebert, S.C. 1996. Molecular site for nucleotide binding on an ATP-sensitive renal $\mathrm{K}^{+}$channel (ROMK2). Am. J. Physiol. 271:F275-F285.

63. Wang, W., and Giebisch, G. 1991. Dual effect of adenosine triphosphate on the apical small conductance $\mathrm{K}^{+}$channel of the rat cortical collecting duct. J. Gen. Physiol. 98:35-61.

64. Hebert, S.C., Friedman, P.A., and Andreoli, T.E. 1984. Effects of antidiuretic hormone on cellular conductive pathways in mouse medullary thick ascending limbs of Henle: I. ADH increases transcellular conductive pathways. J. Membr. Biol. 80:201-219.

65. Field, M.J., Stanton, B.A., and Giebisch, G. 1984 Influence of $\mathrm{ADH}$ on renal potassium handling: a micropuncture and microperfusion study. Kidney
Int. 25:502-511.

66. Cassola, A.C., Giebisch, G., and Wang, W. 1993. Vasopressin increases density of apical low-conductance $\mathrm{K}^{+}$channels in rat CCD. Am. J. Physiol. 264:F502-F509.

67. Schafer, J.A., and Troutman, S.L. 1986. Effect of $\mathrm{ADH}$ on rubidium transport in isolated perfused rat cortical collecting tubules. Am. J. Physiol. 250:F1063-F1072.

68. Schafer, J.A., Troutman, S.L., and Schlatter, E. 1990. Vasopressin and mineralocorticoid increase apical membrane driving force for $\mathrm{K}^{+}$secretion in rat CCD. Am. J. Physiol. 258:F199-F210.

69. Holland, A.E., Wilson, J.W., Kotsimbos, T.C., and Naughton, M.T. 2003. Metabolic alkalosis contributes to acute hypercapnic respiratory failure in adult cystic fibrosis. Chest. 124:490-493.

70. Bates, C.M., Baum, M., and Quigley, R. 1997. Cystic fibrosis presenting with hypokalemia and metabolic alkalosis in a previously healthy adolescent. J. Am. Soc. Nephrol. 8:352-355.

71. Grubb, B.R., and Gabriel, S.E. 1997. Intestinal physiology and pathology in gene-targeted mouse models of cystic fibrosis. Am. J Physiol. 273:G258-G266. 